\title{
Biotin molecules on nitrogen-doped carbon nanotubes enhance the uniform anchoring and formation of Ag nanoparticles
}

\author{
Viviana Jehová González ${ }^{1}$, Eduardo Gracia-Espino², Aarón Morelos-Gómez ${ }^{3}$, Florentino López- \\ Urías $^{4 *}$, Humberto Terrones ${ }^{5}$, and Mauricio Terrones ${ }^{3,6,7}$
}

\begin{abstract}
${ }^{1}$ Departamento de Ciencia e Ingeniería de Materiales e Ingeniería Química, Universidad Carlos III, Av. Universidad 30, 28911 Leganés, Madrid, Spain.

${ }^{2}$ Department of Chemistry and Department of Physics, Umeå University, 90187 Umeå, Sweden.

${ }^{3}$ Institute of Carbon Science and Technology, Shinshu University, 4-17-1 Wakasato, Nagano-city 380-8553, Japan.

${ }^{4}$ Advanced Materials Department, IPICYT, Camino a la Presa San José 2055, Col. Lomas 4a sección, San Luis Potosí S.L.P., 78216, México.

${ }^{5}$ Department of Physics, Applied Physics and Astronomy, Rensselaer Polytechnic Institute, 110 Eighth Street, Troy, NY 12180, USA.

${ }^{6}$ Department of Physics and Center for 2-Dimensional and Layered Materials, The Pennsylvania State University, University Park, PA 16802, USA.

${ }^{7}$ Department of Chemistry, Department of Materials Science and Engineering and Materials Research Institute, The Pennsylvania State University, 104 Davey Lab., University Park, PA 16802-6300, USA.
\end{abstract}

\begin{abstract}
An efficient method for anchoring silver nanoparticles (Ag-NPs) on the surface of nitrogendoped multi-walled carbon nanotubes $\left(\mathrm{CN}_{\mathrm{x}}-\mathrm{MWCNTs}\right)$ is reported. The process involves the attachment of biotin molecules on the surface of $\mathrm{CN}_{\mathrm{x}}$-MWCNTs (both, pristine and acid treated) that act as a reducing agent for $\mathrm{AgNO}_{3}$, thus generating an efficient and homogeneous coating of Ag-NPs $\left(\sim 3 \mathrm{~nm}\right.$ in diameter). The reduction of $\mathrm{AgNO}_{3}$ on either pristine $\mathrm{CN}_{\mathrm{x}}-\mathrm{MWCNTs}$ or acid treated $\mathrm{CN}_{\mathrm{x}}$-MWCNTs (without biotin) results in Ag-NPs of large diameters and size distribution, in addition to a low anchoring efficiency. We confirmed that the use of biotin substantially improves the Ag-NPs anchoring efficiency, especially on acid treated $\mathrm{CN}_{\mathrm{x}}$-MWCNTs. In order to elucidate the mechanism whereby Ag-NPs strongly bind to the surface of $\mathrm{CN}_{\mathrm{x}}-\mathrm{MWCNTs}$, density functional theory (DFT) calculations were carried out. These revealed the existence of covalent bonds established between one side of the biotin molecule and the $\mathrm{CN}_{\mathrm{x}}$-MWCNT surface through oxygen atoms, leaving accessible the exposed sulfur atoms at the other end, which further provided an excellent interaction with the Ag-NPs via S-Ag bonds. Finally, we demonstrate that these AgNPs coated $\mathrm{CN}_{\mathrm{x}}-\mathrm{MWCNT}$ s could be used as efficient sensors of $\mathrm{CS}_{2}$.
\end{abstract}

Keywords: Biotin, silver, nanoparticles, nitrogen-doping, nanotubes.

*Towhom correspondence should be addressed: flo@ipicyt.edu.mx

Corresponding author: Tel/Fax: $+14448342000($ ext. 7238)/+1 4448342040 


\section{Introduction}

Carbon nanotubes (CNTs) have attracted the attention of numerous scientists due to their possible applications in different areas such as mechanical reinforcement in polymer composites [1], as active materials in gas sensors [2,3], bio-sensors [4,5], and drug deliverers [6]. However, CNTs (e.g. MWCNTs) exhibit an almost chemically inert surface, which complicates their interaction with different atomic species. Therefore, surface functionalization of CNTs is necessary in order to improve its interaction with their surroundings. There are several routes used to increase the CNT reactivity. While most of them use acid treatments, the tube surface of CNTs gets partially damaged, thus giving rise to vacancies, dangling bonds, and diverse radicals and functional groups on the nanotubes' surface. Other methods involve the doping of CNTs by introducing diverse hetero-atoms such as $\mathrm{B}, \mathrm{N}, \mathrm{Si}, \mathrm{P}$, etc. within the nanotube's lattice [7-9]. Doping in carbon nanotubes with nitrogen, phosphorus, and boron, generally induces charge redistribution along the defective area enhancing diverse electronic features and improving the surface reactivity [8-11]. However, the extensive literature, simple and inexpensive synthesis procedures used to obtain large amounts of $\mathrm{N}$-doped nanocarbons, additionally to the higher nitrogen incorporation, controllable doping configurations [12], improved biocompatibility [13-15] and substrate reactivity for particle depositions [16-18] makes them an excellent candidate for diverse applications. This is not the case for B-doped nanocarbons, where dangerous and expensive reagents are used $[8,19]$, also the low incorporation of heteroatoms and less diversity on doping configurations limits the usability of these doped systems. In addition, nitrogen-doped multi-walled carbon nanotubes $\left(\mathrm{CN}_{\mathrm{x}}-\mathrm{MWCNTs}\right)$ have proved to be an excellent material for various applications, when compared to undoped MWCNTs [10-13].

In the case of nanoparticles (NPs) decorating CNTs, sensitive hybrid devices could be fabricated in which the metal nanoparticles act as reactive sites for the adsorption of chemical and/or biological species. The decoration of CNTs with metal NPs are of potential interest for catalysis involving fuel cells [20], hydrogen storage [21], photo-electrochemical cells [22], and sensing devices [23], in which the interaction between NPs and the CNT surface might occurs via covalent or non-covalent bonding [24]. In particular, carbon nanotubes decorated with silver nanoparticles (Ag-NPs) have specific interest in the study of surface enhanced Raman spectroscopy (SERS) [25,26], antimicrobial agents [27], $\mathrm{pH}$ and gas sensors [28,29], fuel cells [30], and water purification systems [31], among others. 
The functionalization and subsequent anchorage of NPs on carbon nanotubes can be improved through the use of thiolated groups that provide an ideal driving force for the self-assembly of NPs, thus improving the homogeneity and NP size reduction. Examples of nanotube decoration using these groups can be observed in Pd NPs where benzyl mercaptan [32] was used, Au with alkanedithiols [33], Pt with the thiolation of carbon nanotubes [34], and the use of thiophene for $\mathrm{ZnO}$ NPs [18]. Although, there are some reports on the functionalization of CNTs with biotin [3537], where the biotin contains a thionyl group, to the best of our knowledge there are no reports on using this biomolecule to efficiently anchor Ag-NPs to $\mathrm{CN}_{\mathrm{x}}$-MWCNTs.

In this work, we present an efficient method to obtain small Ag-NPs (ca. $3 \mathrm{~nm})$ with narrow size distribution on $\mathrm{CN}_{\mathrm{x}}$-MWCNTs using biotin as a molecular linkers. The effect of acid treatment on the $\mathrm{CN}_{\mathrm{x}}$-MWCNTs and its role on the deposition efficiency are also investigated; additionally we tested our hybrid material as a $\mathrm{CS}_{2}$ gas sensor.

\section{Experimental procedures}

Material preparation: The $\mathrm{Ag}$ decorated $\mathrm{CN}_{\mathrm{x}}$-MWCNTs are prepared using the following procedure: First, $\mathrm{CN}_{\mathrm{x}}-\mathrm{MWCNTs}$ are synthesized via CVD as described in Ref. [38]. Acid treated $\mathrm{CN}_{\mathrm{x}}$-MWCNTs are prepared using an acidic solution (3:1 in volume) of sulfuric acid $\left(\mathrm{H}_{2} \mathrm{SO}_{4}\right)$ and nitric acid $\left(\mathrm{HNO}_{3}\right)$ in an ultrasonic bath for 5 hours. Subsequently, the $\mathrm{CN}_{\mathrm{x}}-\mathrm{MWCNTs}$ are filtered and washed with a $0.01 \mathrm{M}$ solution of sodium hydroxide $(\mathrm{NaOH})$ and rinsed with distilled water. The biotinized $\mathrm{CN}_{\mathrm{x}}-\mathrm{MWCNTs}$ are prepared by adding $\mathrm{CN}_{\mathrm{x}}-\mathrm{MWCNTs}$ (as produced or acid treated) and biotin powder (3:1 in weight) in a solution containing $4 \mathrm{ml}$ of dimethyl sulfoxide (DMSO) and $36 \mathrm{ml}$ of ethanol (EtOH), the suspension is sonicated for 30 minutes. Afterwards, the suspension is kept for 48 hours at room temperature. Finally, the biotinized samples are filtered and washed with distilled water to remove non-bonded biotin. Once the biotinized $\mathrm{CN}_{\mathrm{x}}-\mathrm{MWCNTs}$ are obtained, the Ag-NPs deposition is performed by adding $5 \mathrm{mg}$ of $\mathrm{CN}_{\mathrm{x}}$-MWCNTs and $83.3 \mu \mathrm{l}$ of silver nitrate solution ( $0.1 \mathrm{M}$ of $\left.\mathrm{AgNO}_{3}\right)$ in deionized water. The suspensions are magnetically stirred for $30 \mathrm{~min}$ at $50^{\circ} \mathrm{C}$, and then filtered and washed with deionized water. We have compared the Ag deposition with non-biotinized nanotubes. 
Gas sensors: Four different sensing devices were fabricated on silicon substrates $\left(\sim 1 \mathrm{~cm}^{2}\right)$ by dip coating, using an aqueous suspension ( 1 mg/mL) of (1) $\mathrm{CN}_{\mathrm{x}}-\mathrm{MWCNTs}$, (2) Ag-NPs on biotinized $\mathrm{CN}_{\mathrm{x}}$-MWCNTs, (3) acid treated $\mathrm{CN}_{\mathrm{x}}$-MWCNTs, and (4) Ag-NPs on acid treated $\mathrm{CN}_{\mathrm{x}}-\mathrm{MWCNTs}$. The suspensions are obtained by sonication with an ultrasonic tip for 5 minutes. Afterwards, the silicon substrates are heat treated for $24 \mathrm{hrs}$. at $80{ }^{\circ} \mathrm{C}$, and the electrical junctions are made through silver paint and copper wires.

Material characterization: The samples were characterized using a micro Raman spectroscopy (Renishaw) with laser excitation lines of $514 \mathrm{~nm}$ and $633 \mathrm{~nm}$. The electron microscopy was carried out using a scanning electron microscope (SEM) (XL30 SFEG FEI operated at 10-20 kV), transmission electron microscope (TEM) at $300 \mathrm{kV}$ (FEI TECNAI F30 STWIN G2), atomic force microscope (AFM, JEOL equipment JSPM 5200) in tapping mode, and thermogravimetric analysis (TGA) (Perkin Elmer 6000STA) system heating from $50{ }^{\circ} \mathrm{C}$ to $900{ }^{\circ} \mathrm{C}$ with a rate of $10^{\circ} \mathrm{C} / \mathrm{min}$ under an air flow of $20 \mathrm{~mL} / \mathrm{min}$. The sensing measurements are carried out using a Sourcemeter (Keithley) with Labview ${ }^{\circledR}$ environment. The sensing capacity is tested by placing the samples inside a quartz tube with a controlled temperature and atmosphere. Two channels are used for introducing the $\mathrm{CS}_{2}$ and the argon gas, which is also used to purge the chamber and clean the nanotubes films. Two different exposure intervals are used: 80 s for sensing the $\mathrm{CS}_{2}$ gas and 100 s to purge with argon gas; this process is repeated for five cycles at least.

Computational details: First-principles calculations were performed using the density functional theory (DFT) [39,40] as implemented in the SIESTA code [41] within the generalized gradient approximation (GGA-PBE). Norm-conserving pseudopotentials were used to represent the core electrons [42] and the wave functions were expanded in terms of a numeric pseudo-atomic simplezeta basis, as described by Junquera et al. [43] a real space mesh equivalent to an energy cutoff of $200 \mathrm{Ry}$ was used for the electrostatic potential integrals. In order to simulate the doping of the nanotube, a single nitrogen substitutional doping site was created on a three different carbon nanotubes, a metallic $(5,5)$, a semi-metallic $(9,0)$ and a semiconductor $(10,0)$, the corresponding supercell contains 160, 180 and 200 atoms, respectively. A vacuum region of at least $20 \AA$ between nanotubes in neighbouring supercells is kept to avoid lateral interactions. Given the system's size, gamma point calculations were carried out. In order to simulate adsorption, the molecules of interest were initially positioned $\sim 2.5 \AA$ from the doped site, and the structure is then geometrically relaxed by conjugate gradient geometry optimization until residual forces are $<0.04 \mathrm{eV} / \AA$. The thermal 
stability of the adsorption process was verified by molecular dynamics (MD) using a time step of 1 fs for the integration of the equations of motion, for a minimum of 1000 steps. The temperature of 50 and $300 \mathrm{~K}$ was controlled by the Nose thermostat, using a Nose mass of $10.0 \mathrm{Ry} \cdot \mathrm{fs}^{2}$ [44].

\section{Results and discussion.}

The SEM micrographs of $\mathrm{Ag}$ decorated $\mathrm{CN}_{\mathrm{x}}$-MWCNTs are shown in Figure 1, where the biotinized $\mathrm{CN}_{\mathrm{x}}$-MWCNTs (Figure 1a) exhibit relatively small Ag-NPs, however the Ag-NPs possess different sizes and are distributed non-homogeneously on the surface of nanotubes. Figure $1 \mathrm{~b}$ displays the pristine $\mathrm{CN}_{\mathrm{x}}$-MWCNTs (without biotin or acid treatment) mixed only with DMSO, yielding a poor formation of Ag-NPs. Due to the low decoration efficiency, we pre-functionalized the carbon nanotubes by an acid treatment (before the biotinization process), in order to increase the anchoring sites on the nanotubes surface. As a result, diverse types of defects are created within the nanotubes lattice, thus improving their chemical activity. Afterwards, the biotinization process and the anchoring procedure are repeated, the results are shown in Figure 1(c-d). We observe that nonbiotinized $\mathrm{CN}_{\mathrm{x}}$-MWCNTs, neither pristine nor acid treated, exhibit lower amounts of Ag-NPs on their surface (Figure $1 \mathrm{~b}$ and d) when compared with biotinized $\mathrm{CN}_{\mathrm{x}}-\mathrm{MWCNTs}$ (Figure 1a and c).

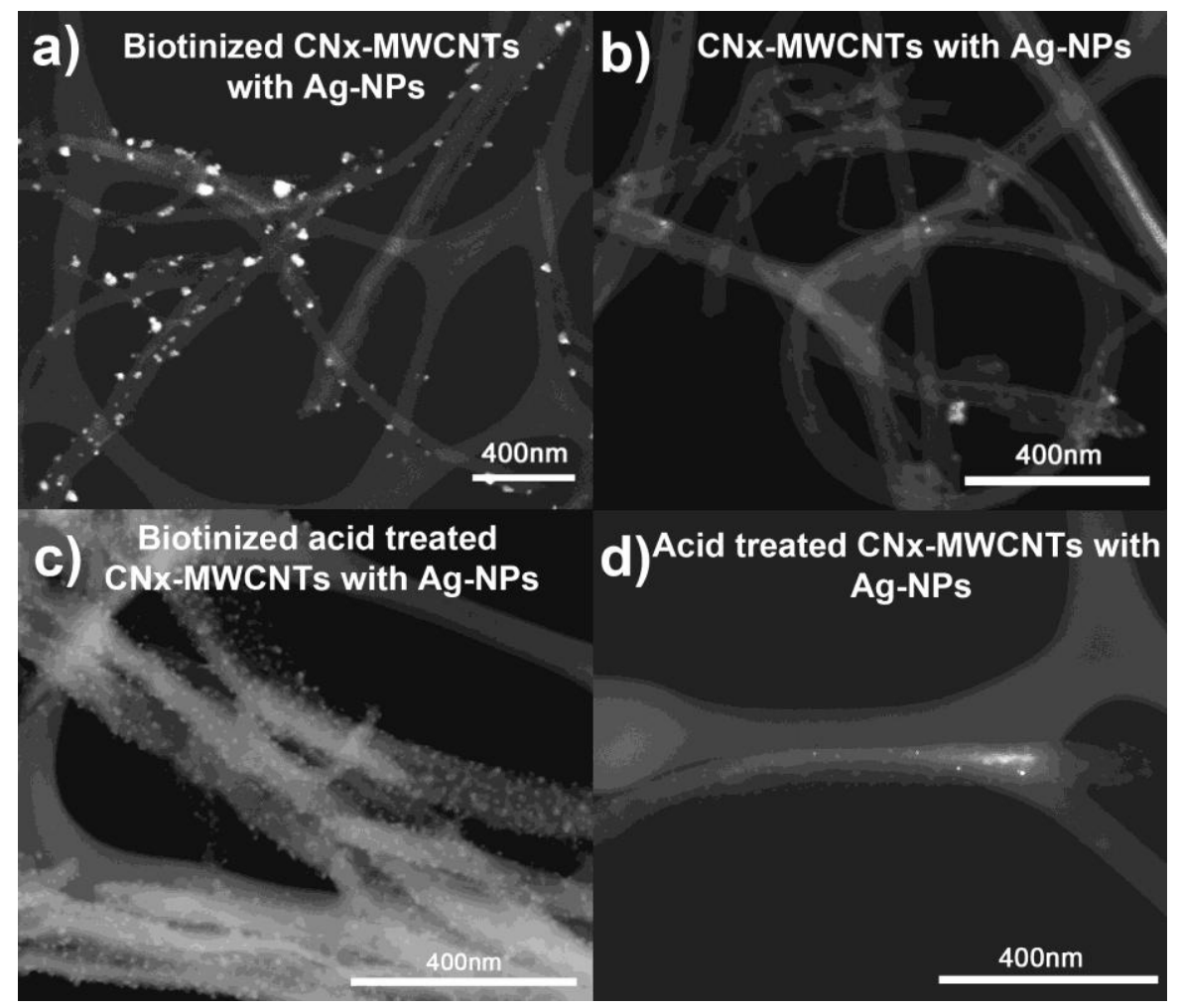

Fig.1. SEM micrographs of Ag-NPs anchored on different $\mathrm{CN}_{\mathrm{x}}-\mathrm{MWCNTs}$. a) Biotinized $\mathrm{CN}_{\mathrm{x}^{-}}$ MWCNTs. b) pristine $\mathrm{CN}_{\mathrm{x}}$-MWCNTs. c) acid treated $\mathrm{CN}_{\mathrm{x}}$-MWCNTs with biotin. d) Acid treated 
$\mathrm{CN}_{\mathrm{x}}$-MWCNTs. Note the smaller diameter and improved distribution of Ag-NPs in c).

In order to confirm the presence of $\mathrm{Ag}$ in our tube material, energy dispersive X-ray (EDX) analyses were carried out and the results are shown in Figure 2. Note that biotinized composites (biotinized $\mathrm{CN}_{\mathrm{x}}-\mathrm{MWCNT}$ and acid treated $\mathrm{CN}_{\mathrm{x}}-\mathrm{MWCNTs}$ with biotin. Figure $2 \mathrm{~b}$ and $2 \mathrm{~d}$ ) exhibit considerable quantities of $\mathrm{Ag}$, corresponding to $11.6 \mathrm{wt} \%$ and $31.0 \mathrm{wt} \%$ of $\mathrm{Ag}$ (from $\mathrm{EDX}$ analyses), respectively. Interestingly, the presence of $\mathrm{Ag}$ is minimal on the non-biotinized composites. X-ray powder diffraction (XRD) studies reveal a well crystalline structure corresponding to a face-centered cubic (fcc) phase for Ag-NPs (see Figure 3). Due to the outstanding nanoparticle decoration of biotinized nanotubes, we focused our study on biotinized $\mathrm{CN}_{\mathrm{x}}$-MWCNTs and acid treated $\mathrm{CN}_{\mathrm{x}}$-MWCNTs with biotin. High resolution electron microscopy (HRTEM) images are shown in Figure 4. Here it is possible to observe that in both systems Ag-NPs are anchored on the nanotubes surfaces; the NPs exhibit a spherical-like shape with diverse diameters. For biotinized $\mathrm{CN}_{\mathrm{x}}$-MWCNTs the average nanoparticle size is $c a .12 \mathrm{~nm}$ (Figure 4a-b), while the acid treated $\mathrm{CN}_{\mathrm{x}}-\mathrm{MWCNTs}$ with biotin (Figure $4 \mathrm{c}-\mathrm{d}$ ) exhibit a much smaller diameter of ca. $3 \mathrm{~nm}$, with a well-defined crystalline structure, as suggested by XRD analysis (see Figure 3). It is also notable the excellent coverage of small Ag-NPs along the nanotubes surface, Figure $4 \mathrm{~d}$ clearly shows that Ag-NPs are anchored to the nanotubes' surface. 


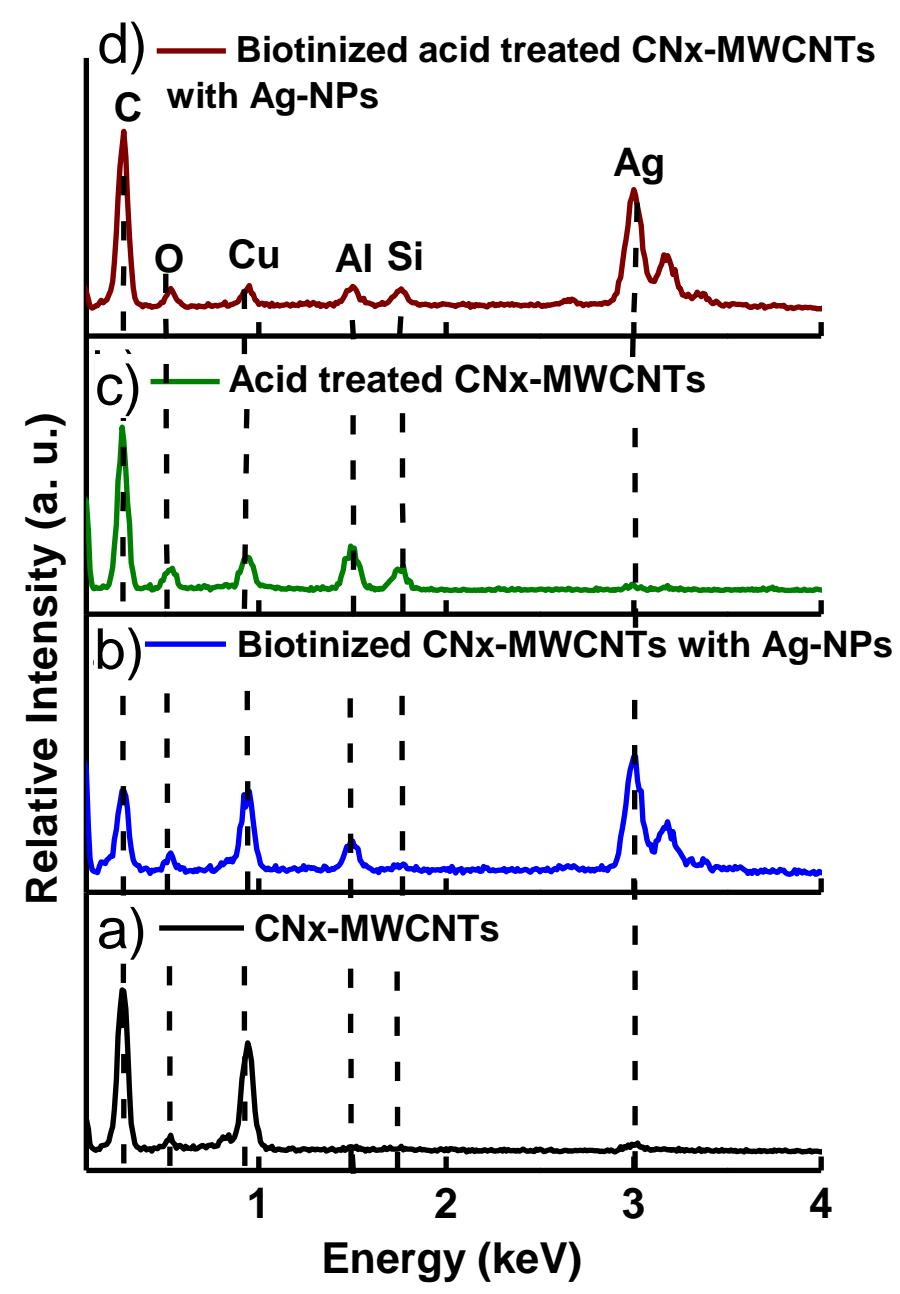

Fig. 2. Energy dispersive X-ray spectroscopy (EDX) spectra of Ag-NPs deposited on different $\mathrm{CN}_{\mathrm{x}^{-}}$ MWCNT samples. a) $\mathrm{CN}_{\mathrm{x}}-\mathrm{MWCNTs}$, b) Biotinized $\mathrm{CN}_{\mathrm{x}}-\mathrm{MWCNTs}$, c)acid treated $\mathrm{CN}_{\mathrm{x}^{-}}$ MWCNTs, and d) acid treated $\mathrm{CN}_{\mathrm{x}}$-MWCNTs with biotin. The corresponding SEM images are shown in Figure 2. Note that both biotinized samples (a and c) exhibit significant quantities of silver of 11.6 and $31.0 \% \mathrm{wt}$, respectively. 


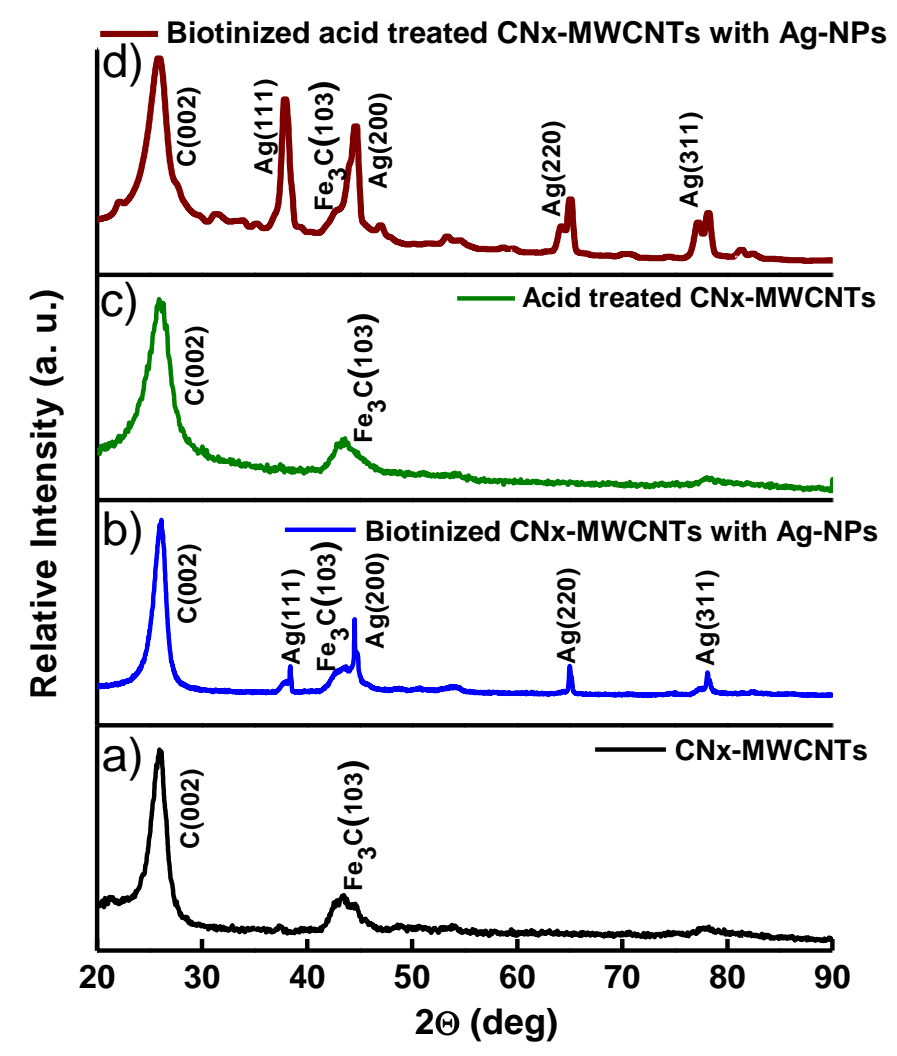

Fig 3. X-ray diffraction patterns of a) $\mathrm{CN}_{\mathrm{x}}-\mathrm{MWCNTs}$. b) Ag-NPs deposited on biotinized $\mathrm{CN}_{\mathrm{x}^{-}}$ MWCNTs, $\mathbf{c}$ ) acid treated $\mathrm{CN}_{\mathrm{x}}$-MWCNTs and d) Ag-NPs deposited on acid treated $\mathrm{CN}_{\mathrm{x}}$-MWCNTs. Note that the Ag-NPs exhibit a well defined face-centered cubic (fcc) crystalline phase. 


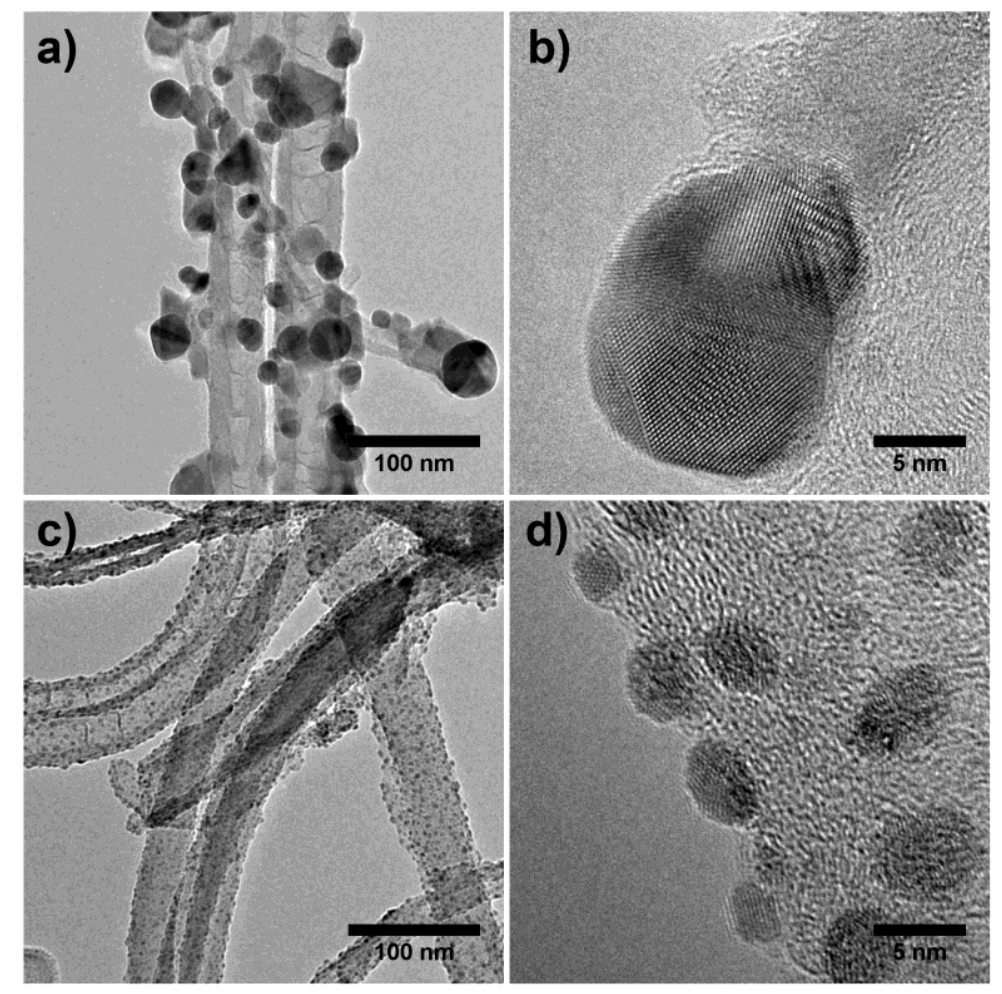

Fig. 4. TEM images of Ag-NPs deposited on biotinized $\mathrm{CN}_{\mathrm{x}}-\mathrm{MWCNTs}$. a-b) correspond to biotinized $\mathrm{CN}_{\mathrm{x}}$-MWCNTs. c-d) correspond to acid treated $\mathrm{CN}_{\mathrm{x}}-\mathrm{MWCNTs}$ covered with biotin. High resolution micrograph in d) reveals that the Ag-NPs are crystallographically ordered, as suggested by XRD.

Size distributions of Ag-NPs for both biotinized composites are depicted in Figure 5; the distribution is obtained by measuring at least 250 nanoparticles from diverse TEM micrographs. Here, we clearly observe the synergistic effect of the acid treatment and biotin passivation on decreasing considerably both particle diameter and size distribution, when compared with the nanotubes without the acid treatment. The average particle size for acid treated and biotinized nanotubes is $3 \pm 1.06 \mathrm{~nm}$, which is four times smaller when compared with the sample without acid treatment (particle size equal to $12 \pm 4.76 \mathrm{~nm}$ ). These results are consistent considering that nanotubes without acid treatment have fewer anchoring sites and poor interaction with biotin, and thus the excess of silver in the solution promotes larger nanoparticles. On the other hand, acid treated nanotubes exhibit a considerably number of defects, and an improved interaction with biotin, all these will later contribute to improve the nanotube decoration and growing smaller nanoparticles. 

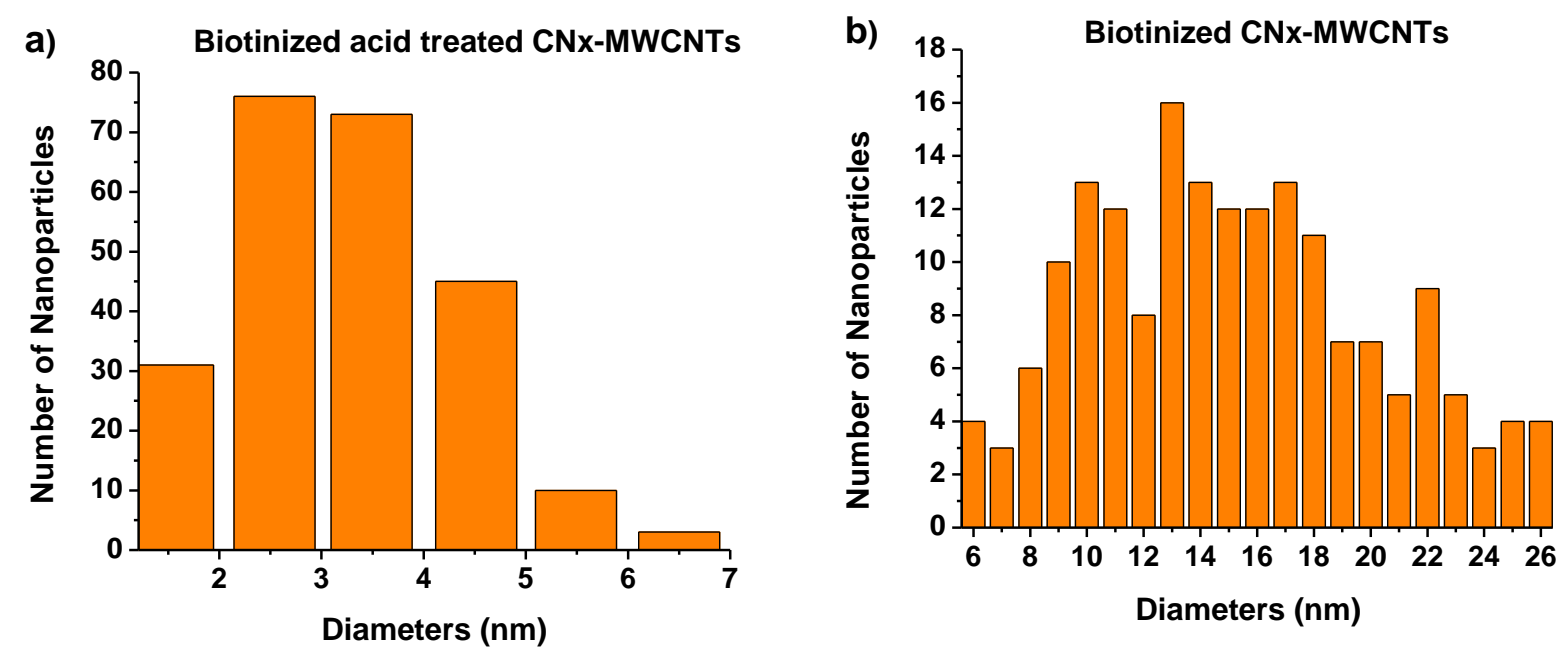

Fig. 5. Size distribution of Ag-NPs deposited on $\mathrm{CN}_{\mathrm{x}}-\mathrm{MWCNTs}$. a) Sample corresponding to acid treated $\mathrm{CN}_{\mathrm{x}}$-MWCNTs with biotin, the Ag-NPs exhibit a diameter equal to $3 \pm 1.06 \mathrm{~nm}$. b) Biotinized $\mathrm{CN}_{\mathrm{x}}$-MWCNTs, here the particles exhibit wider size distribution with average diameter equal to $12 \pm 4.76 \mathrm{~nm}$.

We have analyzed the Raman spectra of the different samples considered in our study, the results are shown in Figure 6. In general, we observe that the D- and G-bands in Raman spectra are upshifted after the biotinization process (see the vertical dashed line in Figures $6 \mathrm{a}$ and Figure $6 \mathrm{~b}$ ), indicating slight structural modifications on the nanotubes. Biotinized $\mathrm{CN}_{\mathrm{x}}-\mathrm{MWCNTs}$ exhibit a Dand G-bands upshift equal to 11 and $5 \mathrm{~cm}^{-1}$, respectively. Similarly, the D- and G-bands of biotinized acid-treated nanotubes are upshifted by 21 and $3 \mathrm{~cm}^{-1}$, respectively. This effect could be related by charge transfer between biotin and carbon nanotubes via p-type doping [45]. We have also analyzed the D- and G-bands intensity ratio $\left(\mathrm{I}_{\mathrm{D}} / \mathrm{I}_{\mathrm{G}}\right)$. We noted that the $\mathrm{I}_{\mathrm{D}} / \mathrm{I}_{\mathrm{G}}$ of biotinized $\mathrm{CN}_{\mathrm{x}^{-}}$ MWCNTs slightly decreases after the biotinization process, from 0.737 to 0.613 for non-biotinized and biotinized nanotubes, respectively. Similar results were obtained for $\mathrm{CN}_{\mathrm{x}}$-MWCNTs treated with acid in the Figure $6 b$. However, in this case we observed an increase in the $I_{D} / I_{G}$ ratio, from 0.777 to 0.891 after biotinization. This increase indicates a decrease in the degree of crystallinity induced by the presence of biotin molecules on the tubes' surface [46] (see Figure 6b). In general, these defects are chemically active, and promote the anchoring of different molecules on the tubes's surface. 

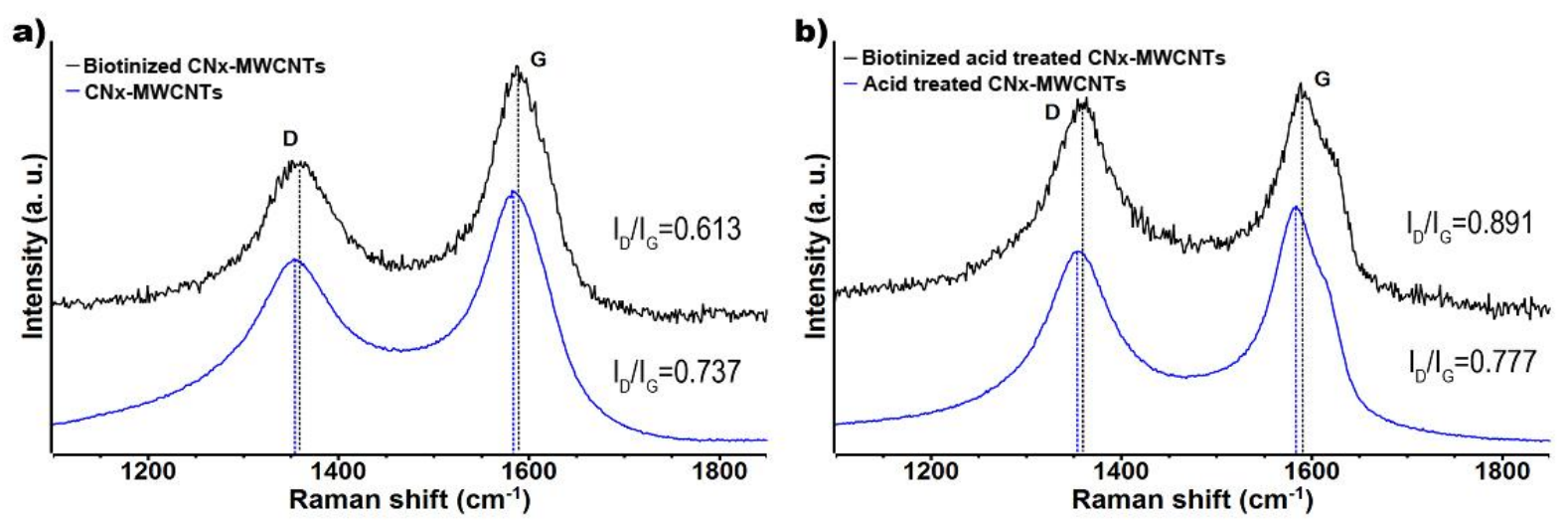

Fig. 6. Raman spectra for different samples considered in our study. The signals correspond to $\mathrm{CN}_{\mathrm{x}^{-}}$ MWCNTs in different conditions: a) $\mathrm{CNx}-\mathrm{MWCNT}$ and biotinized $\mathrm{CN}_{\mathrm{x}}$-MWCNTs, b) acid treated $\mathrm{CN}_{\mathrm{x}}$-MWCNTs and acid treated CNx-MWCNTs with biotin. Notice that the spectrum of biotinized nanotubes exhibits an upshift with respect to non-biotinized nanotubes (see vertical dashed lines). Regarding acid treated $\mathrm{CN}_{\mathrm{x}}-\mathrm{MWCNTs}$, the ratio between the D- and G-peak intensities increases suggesting disorder in the nanotube's lattice. The black line is used for biotinized composites, and blue line for non-biotinized materials.

\section{Theoretical description of Ag-CN - $-\mathrm{MWCNTs}$ composites.}

In order to gain insight into the decoration mechanism and investigate the role of biotin in our experiments, we have performed ab initio calculations using density functional theory (DFT). Our DFT analysis suggests that the possible anchoring mechanism is conducted via a biotin bridge between the nanotubes and Ag-NPs surfaces, thus promoting considerably the anchoring efficiency. We initiated our DFT analysis by placing a biotin molecule at $\sim 2.5 \AA$ above a nitrogen-doped $(5,5)$ single-walled carbon nanotube $\left((5,5)-\mathrm{CN}_{\mathrm{x}}-\mathrm{SWCNT}\right)$, see details in computational methods, and then geometrically optimized. We found that the most favorable adsorption configuration exhibit the oxygenated "tail" of biotin directly attached to the nanotube's wall by a direct bonding to a $\mathrm{C}$ atom near the doping site, a result which is in good agreement with previous publications in which atoms surrounding the doping site exhibit higher chemical reactivity [47]. The optimized structure of the adsorbed biotin molecule on the $(5,5)-\mathrm{CN}_{\mathrm{x}}-\mathrm{SWCNT}$ via an oxygen atom is shown in Figure $7 \mathrm{a}$. Now, when using the structure shown in Figure $7 \mathrm{a}$ as the starting geometry, we studied the adsorption of single $\mathrm{Ag}_{13}$ cluster with icosahedral geometry; note that due the small cluster size with 
an icosahedral geometry is preferred over the cuboctahedral [48]. Figure $7 \mathrm{~b}$ depicts the optimized structure of the biotinized $\mathrm{Ag}_{13}-(5,5)-\mathrm{CN}_{\mathrm{x}}-\mathrm{SWCNT}$ system. It is important to point out that after the biotin adsorption (Figure $7 \mathrm{a}$ ), the sulfur atom of the biotin molecule is unsaturated and acts as a strong anchoring site for $\mathrm{Ag}_{13}$ clusters. This is also in good agreement with recently results reported by Gracia-Espino et al. [32], where a sulfurized molecule is used as a linker between the carbon nanomaterial and the metallic nanoparticle; the sulfur atom plays a key role in the anchoring process and results in enhanced anchoring efficiency and smaller nanoparticle diameter. We performed additional calculations using a semiconducting $(10,0)$ and a semi-metallic $(9,0)$ carbon nanotubes. The results suggest that the anchoring mechanism is performed similarly to the $(5,5)$ nanotube, and that apparently the Ag deposition is chiral independent, the optimized geometries after biotin and Ag-cluster adsorption for both $(9,0)$ - and $(10,0)-\mathrm{CN}_{\mathrm{x}}-\mathrm{SWCNT}$ can be seen in supporting information, Figure S4.
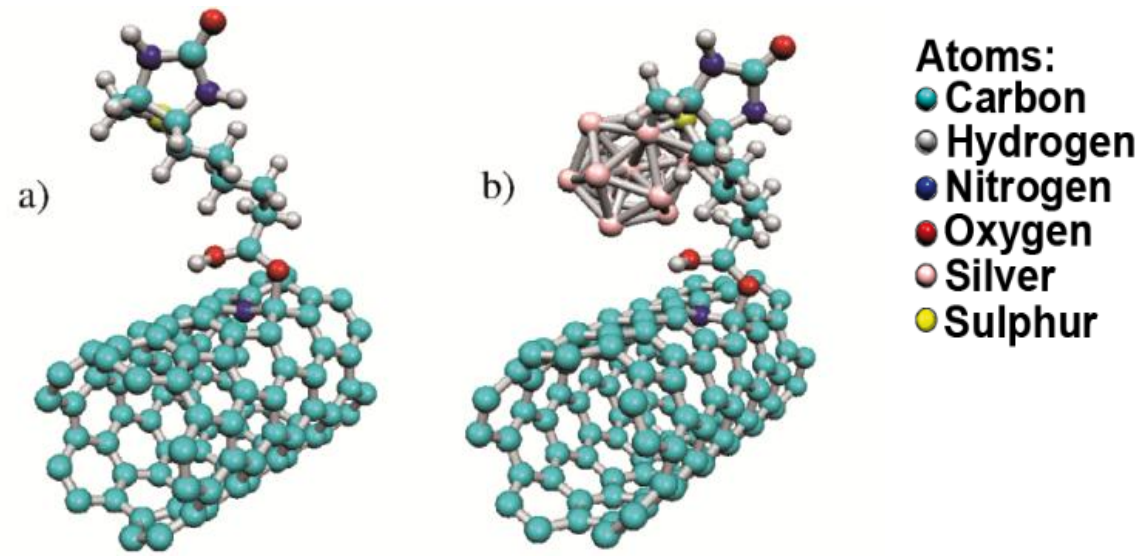

Fig.7. Optimized geometries of the (5,5)- $\mathrm{CN}_{\mathrm{x}}-\mathrm{SWCNT}$ under different conditions. a) Adsorption of biotin on (5,5)-CN $\mathrm{CN}_{\mathrm{x}}-\mathrm{SWCNT}$. b) adsorption an $\mathrm{Ag}_{13}$ icosahedral cluster using a biotin molecule as a linker to the $(5,5)-\mathrm{CN}_{\mathrm{x}}-\mathrm{SWCNT}$ surfaces.

\section{Gas sensing applications of Ag- $\mathrm{CN}_{\mathrm{x}}-\mathrm{MWCNTs}$ composites.}

The excellent distribution and small diameter of Ag-NPs of our systems makes them an interesting material for diverse applications, such as gas sensing. In this context, we have complemented our studies by analyzing the $\mathrm{CS}_{2}$ sensing capabilities of the Ag- $\mathrm{CN}_{\mathrm{x}}-\mathrm{MWCNT}$ s hybrid composites. The sensor fabrication and set-up details are present in the methodology section. We prepared four different types of sensor devices, and then recorded the electrical resistance as a function of time 
during the $\mathrm{CS}_{2}$ gas exposure and the results are depicted in Figure 8. We observe that the adsorption of $\mathrm{CS}_{2}$ gas decreases the electrical resistance of the nanotube film. The reduction of electrical resistance $(\Delta R)$ upon the presence of $C_{2}$ gas strongly depends on the hybrid system, in which the values of $\Delta \mathrm{R}$ are observed as follows: Ag-NPs-acid treated $\mathrm{CN}_{\mathrm{x}}-\mathrm{MWCNTs}(8.93 \%)>\mathrm{Ag}$-NPsbiotinized $\mathrm{CN}_{\mathrm{x}}-\mathrm{MWCNTs}(6.35 \%)>\mathrm{CN}_{\mathrm{x}}-\mathrm{MWCNTs}(3.17 \%)>$ Acid treated $\mathrm{CN}_{\mathrm{x}}-\mathrm{MWCNTs}$ (1.98\%). All hybrid $\mathrm{CN}_{\mathrm{x}}-\mathrm{MWCNTs}$ decorated with Ag-NPs exhibit an improved response when compared to $\mathrm{CN}_{\mathrm{x}}$-MWCNTs without Ag NPs, showing in all the cases a small chemisorption in the sensor response. Interestingly, the material with the best performance is the Ag-NPs-acid treated $\mathrm{CN}_{\mathrm{x}}-\mathrm{MWCNTs}$, and not the Ag-NPs-biotinized $\mathrm{CN}_{\mathrm{x}}-\mathrm{MWCNTs}$, as depicted in Figure $8 \mathrm{c}$ and $8 \mathrm{~d}$. In both cases, the carbon nanotube structures are damaged creating several types of defects which are potentially important for nanoparticles attachment, as TEM and HRTEM characterizations demonstrate. However, as our results indicate, in the Ag-NPs-biotinized $\mathrm{CN}_{\mathrm{x}}-\mathrm{MWCNTs}$ composite, the biotin molecules passivate the Ag-nanoparticles, improving the homogeneity and decreasing the particle size, but also covers most of its surface and thus difficult the interaction between the Agnanoparticles and $\mathrm{CS}_{2}$ gas. This excessive passivation might minimize the $\mathrm{CS}_{2}$ gas adsorption causing a considerably reduction in the sensor sensitivity.
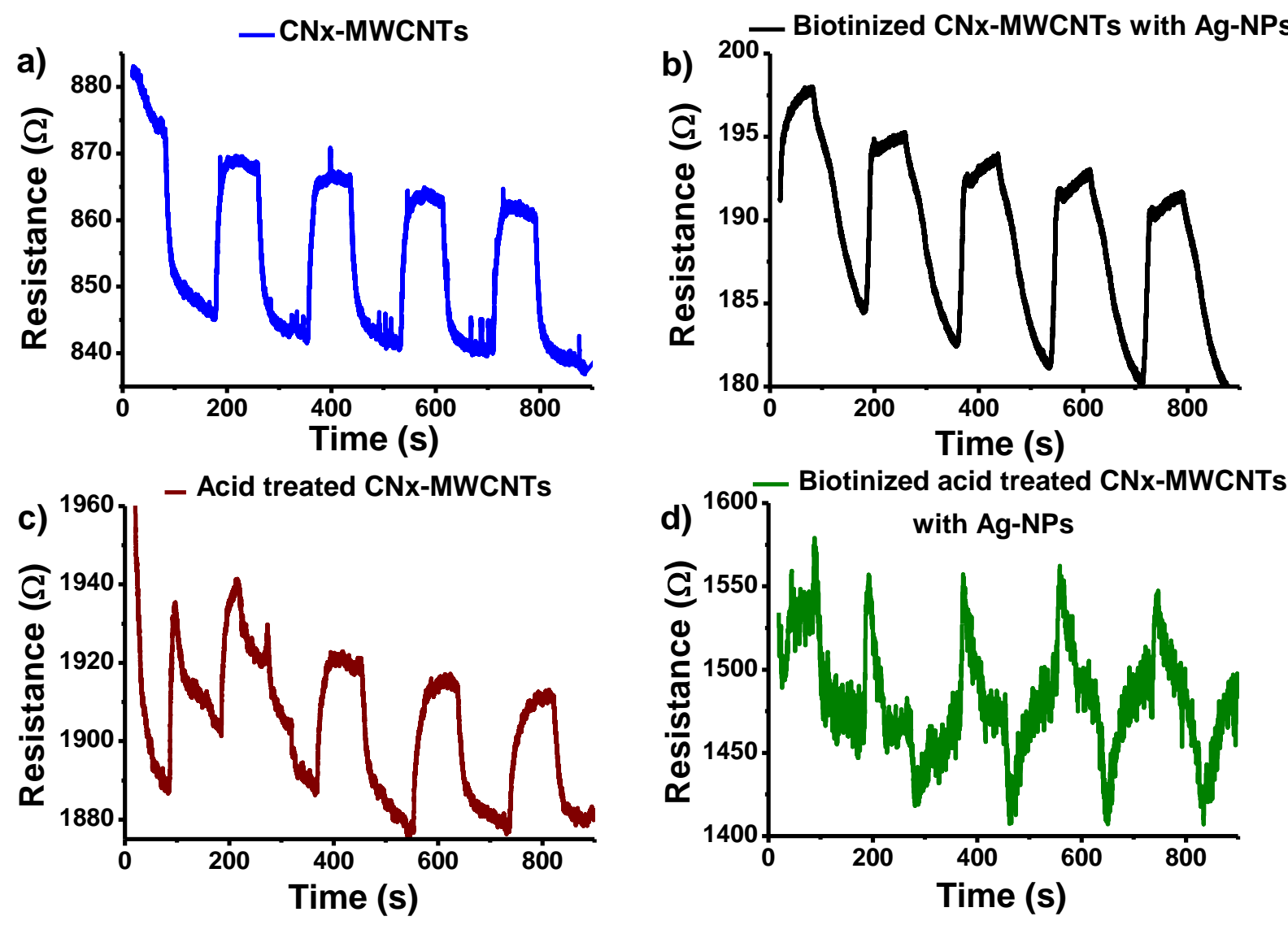
Fig.8. Electrical resistance in presence of $\mathrm{CS}_{2}$ for a) $\mathrm{CN}_{\mathrm{x}}-\mathrm{MWCNTs}$, b) Ag-NPs deposited on biotinized $\mathrm{CN}_{\mathrm{x}}-\mathrm{MWCNTs}$, c) acid treated $\mathrm{CN}_{\mathrm{x}}-\mathrm{MWCNTs}$ and d) Ag-NPs deposited on acid treated $\mathrm{CN}_{\mathrm{x}}$-MWCNTs.

\section{Conclusions}

$\mathrm{CN}_{\mathrm{x}}$-MWCNTs covered with biotin molecules and Ag-NPs were synthesized and characterized using different techniques. Raman spectroscopy demonstrated that biotin molecules are indeed anchored to the nanotube's surface through defects (possibly vacancies and other functional groups). In addition, shifts in the D- and G-bands were observed for biotinized $\mathrm{CN}_{\mathrm{x}}-\mathrm{MWCNTs}$, thus indicating that the vibrational modes of CNTs were modified due to the interactions with biotin. SEM, TEM and AFM characterization revealed that when the $\mathrm{CN}_{\mathrm{x}}-\mathrm{MWCNT}$ are treated with acid and then biotinized, the Ag-NPs exhibit smaller average diameter and they are homogeneously distributed along the nanotubes surface. DFT calculations demonstrated that Ag clusters are stable and well attached to the surface of nitrogen-doped carbon nanotubes where the biotin is used as molecular linker. It is noteworthy that $\mathrm{CN}_{\mathrm{x}}-\mathrm{MWCNT}$ s have shown enhanced biocompatibility when compared to pristine and other types of doped MWCNTs. Therefore, the materials produced here might find unprecedented applications as bactericides, composites, bio-sensing and other biooriented devices and applications.

\section{Acknowledgments}

MT thanks JST-Japan for funding the Research Center for Exotic NanoCarbons, under the Japanese regional Innovation Strategy Program by the Excellence. MT also thanks the Penn State Center for Nanoscale Science for seed grant entitled on 2-D Layered Materials. E.G.E. acknowledges support from the Artificial Leaf Project Umeå (K\&A Wallenberg foundation) and the ÅForsk foundation (14-541). The authors are grateful to the Materials Research Institute at Penn State for the usage of characterization facilities. The theoretical simulations were partially 
performed on resources provided by the Swedish National Infrastructure for Computing (SNIC) at the High Performance Computing Center North (HPC2N).

\section{References}

1. Liu, Y. Kumar, S. Polymer/Carbon Nanotube Nano Composite Fibers-A Review, ACS Appl. Mater. Interfaces, 2014; 6: 6069-6087.

2. Tasca, F. Gorton, L. Wagner, JB. Nöll, G. Increasing Amperometric Biosensor Sensitivity by Length Fractionated Single-Walled Carbon Nanotubes. Biosens. Bioelectron 2008; 24: 272-278.

3. Tasis D, Tagmatarchis N, Bianco A, Prato M. Chemistry of carbon nanotubes. Chem. Rev. 2006; 106: 1105-1136.

4. Balasubramanian K, Burghard M. Biosensors based on carbon nanotubes. Anal. Bioanal. Chem.2006; 385: 452-468.

5. Besteman K, Lee JO, Wiertz FGM, Heering HA, Dekker C. Enzyme-coated carbon nanotubes as single-molecule biosensors. Nano Lett. 2003; 3: 727-730.

6. Bianco A, Kostarelos K, Prato M. Applications of carbon nanotubes in drug delivery. Curr. Opin. Chem. Biol. 2005; 9: 674-679.

7. Jiang H, Zhang D, Wang R. Silicon-doped carbon nanotubes: a potential resource for the detection of chlorophenols/chlorophenoxy radicals. Nanotechnology 2009; 20: 145501.

8. Hashim DP, Narayanan NT, Romo-Herrera JM, Cullen DA, Hahm MG, Lezzi P, Suttle JR, Kelkhoff D, Muñoz-Sandoval E, Ganguli S, Roy AK, Smith DJ, Vajtai R, Sumpter BG, Meunier V, Terrones H, Terrones M, Ajayan PM. Covalently bonded three-dimensional carbon nanotube solids via boron induced nanojunctions. Scientific Reports 2012; 2: 363.

9. Cao Y, Yu H, Tan J, Peng F, Wang H, Li J, Zheng W, Wong NB. Nitrogen-, phosphorous- and boron-doped carbon nanotubes as catalysts for the aerobic oxidation of cyclohexane. Carbon 2013; 57: 433-442.

10. Terrones M, Filho AGS, Rao AM. Doped carbon nanotubes: synthesis, characterization and applications in carbon nanotubes: advanced topics in the synthesis, structure, properties and applications. Topics of Applied Physics. Jorio A, Dresselhaus G, Dresselhaus MS, Springer 2008; 531-566.

11. Cruz-Silva E, Lopez-Urias F, Muñoz-Sandoval E, Sumpter BG, Terrones H, Charlier JC, 
Meunier V, Mauricio T. Electronic Transport and Mechanical Properties of Phosphorus- and Phosphorus-Nitrogen-Doped Carbon Nanotubes. ACS Nano 2009; 3: 1913-1921.

12. Sharifi T., Hu G., Jia X., Wågberg T., Formation of Active Sites for Oxygen Reduction Reactions by Transformation of Nitrogen Functionalities in Nitrogen-Doped Carbon Nanotubes. ACS Nano. 2012; 6: 8904-8912.

13. Castle AB, Gracia-Espino E, Nieto-Delgado C, Terrones H, Terrones M, Hussain S. Hydroxylfunctionalized and n-doped multiwalled carbon nanotubes decorated with silver nanoparticles preserve cellular function. ACS Nano 2011; 5: 2458-2466.

14. Elías AL, Carrero-Sánchez JC, Terrones H, Endo M, Laclette JP, Terrones M. Viability Studies of Pure Carbon- and Nitrogen-Doped Nanotubes with Entamoeba histolytica: From Amoebicidal to Biocompatible Structures. Small 2007; 3: 1723-1729.

15. Carrero-Sánchez JC, Elías AL, Mancilla R, Arreguín G, Terrones H, Laclette JP, Terrones M. Biocompatibility and Toxicological Studies of Carbon Nanotubes Doped with Nitrogen. Nano Lett. 2006; 6: 1609-1616.

16. Jiang KY, Eitan A, Schadler LS, Ajayan PM, Siegel RW, Grobert N, Mayne M, Reyes-Reyes M, Terrones H, Terrones M. Selective Attachment of Gold Nanoparticles to Nitrogen-Doped Carbon Nanotubes. Nano Lett.2003; 3: 275-277.

17. Zamudio A, Elías AL, Rodríguez-Manzo JA, López-Urías F, Rodríguez-Gattorno G, Lupo F, Ruhle M, Smith DJ, Terrones H, Díaz D, Terrones M. Efficient anchoring of silver nanoparticles on N-doped carbon nanotubes. Small 2006; 2(3): 346-350.

18. Gracia-Espino E., López-Urías F., Terrones H., Terrones M., Self-Assembly Synthesis of Decorated Nitrogen-Doped Carbon Nanotubes with ZnO Nanoparticles: Anchoring Mechanism and the Effects of Sulfur, J. Phys. Chem. C, 2015; 119: 741-747.

19. Panchakarla, L.S. Govindaraj, A. Rao, C.N.R. Boron- and nitrogen-doped carbon nanotubes and graphene, Inorganica Chimica Acta, 2010; 363: 4163-4174

20. Santhosh P, Gopalan A, Lee KP. Gold nanoparticles dispersed polyaniline grafted multiwall carbon nanotubes as newer electrocatalysts: Preparation and performances for methanol oxidation. J. Catal. 2006; 238: 177-185.

21. Costa PMFJ, Coleman KS, Green MLH. Influence of catalyst metal particles on the hydrogen sorption of single-walled carbon nanotube materials. Nanotechnology 2005; 16 (4), 512-517.

22. Zhang GQ, Zhang XG, Wang YG. A new air electrode based on carbon nanotubes and Ag$\mathrm{MnO}_{2}$ for metal air electrochemical cells. Carbon 2004; 42: 3097.

23. Wu ZY, Chen LG, Shen GL, Yu RQ. Platinum nanoparticle-modified carbon fiber 
ultramicroelectrodes for mediator-free biosensing. Sens. Actuators B 2006; 119: 295-301.

24. Wang T, Hu XG, Qu XH, Dong SJ. Noncovalent functionalization of multiwalled carbon nanotubes: application in hybrid nanostructures. J. Phys. Chem. B 2006; 110, 6631-6636.

25. Chen YC, Young RJ, Macpherson JV, Wilson NR. Single-Walled Carbon Nanotube Networks Decorated with Silver Nanoparticles: A Novel Graded SERS Substrate. J. Phys. Chem. C 2007; 111: 16167-16173.

26. Zhao Q, Buongiorno NM, Lu W, Bernholc J. Carbon nanotube-metal cluster composites: A new road to chemical sensors?. Nano Lett. 2005; 5: 847-851.

27. Yuan W, Jiang G, Che J, Qi X, Xu R, Chang MW, Chen Y, Lim SY, Dai J, Chan-Park MB. Deposition of silver nanoparticles on multiwalled carbon nanotubes grafted with hyperbranched poly(amidoamine) and their antimicrobial effects. J. Phys. Chem. C 2008; 112:18754-18759.

28. Zhao L, Shingaya Y, Tomimoto H, Huang Q, Nakayama TJ. Functionalized carbon nanotubes for pH sensors based on SERS. Mater. Chem. 2008; 18: 4759-4761

29. Espinosa, EH, Ionescu R, Bittencourt C, Felten A, Erni R, Van Tendeloo G, Pireaux JJ, Llobet E. Metal-decorated multi-wall carbon nanotubes for low temperature gas sensing. Thin Solid Films 2007; 515: 8322-8327.

30. Guo DJ, Li HL. Highly dispersed Ag nanoparticles on functional MWCNT surfaces for methanol oxidation in alkaline solution. Carbon 2005; 43:1259-1264.

31. Gunawan P, Guan C, Song X, Zhang Q, Leong SSJ, Tang C, Chen Y, Chan-Park MB, Chang MW, Wang K, Xu R. Hollow FiberMembrane Decorated with Ag/MWCNTs: Toward Effective Water Disinfection and Biofouling Control. ACS Nano 2011; 5: 12: 10033-10040.

32. Gracia-Espino E, Hu G, Shchukarev A, Wagberg T. Understanding the Interface of Six-Shell Cuboctahedral and Icosahedral Palladium Clusters on Reduced Graphene Oxide: Experimental and Theoretical Study. J. Am. Chem. Soc. 2014; 136: 6626-6633.

33. Park S, Kim HR, Kim J, Jung C, Rhee CK, Kwon K, Kim Y. Assembly of strands of multiwall carbon nanotubes and gold nanoparticles using alkanedithiols. Carbon 2011; 49 (2): 487-494.

34. Kim Y.-T, Mitani T. Surface thiolation of carbon nanotubes as supports: A promising route for the high dispersión on Pt nanoparticles for electrocatalysts. J. Catal. 2006; 238: 394-401.

35. Chen R, Zhang Y, Wang D, Dai H. Noncovalent sidewall functionalization of single-walled carbon nanotubes for protein immobilization. J. Am. Chem. Soc. 2001; 123: 3838-3839.

36. Shim M, Wong N, Shi K, Chen RJ, Li Y, Dai H. Functionalization of carbon nanotubes for biocompatibility and biomolecular recognition. Nano Lett. 2002; 2: 285-288. 
37. Star A, Gabriel JCP,Bradley K, Gruner G. Electronic detection of specific protein binding using nanotube FET devices. Nano Lett. 2003; 3:459-463.

38. Terrones M, Terrones H, Grobert N, Hsu WK, Zhu YQ, Hare JP, Kroto HW, Walton DRM, Kohler-Redlich $\mathrm{Ph}$, Ruhle M, Zhang JP, Cheetham AK. Efficient route to large arrays of CNx nanofibers by pyrolysis of ferrocene/melamine mixtures. Appl. Phys. Lett. 1999; 75: 3932-3934.

39. Hohenberg P, Kohn W. Inhomogeneous Electron Gas. Phys. Rev. 1964; 136: B864.

40. Kohn W, Sham LJ. Self-Consistent Equations Including Exchange and Correlation Effects. Phys. Rev. 1965; 140: 1133-1138.

41. Soler JM, Artacho E, Gale JD, Garcia A, Junquera J, Ordejon P, Sanchez-Portal D. The SIESTA method for ab initio order-N materials simulation. J. Phys-Cond Matter 2002; 14:2745-2779.

42. Troullier N, Martins JL. Efficient pseudopotentials for plane-wave calculations. Phys. Rev. B 1991; 43:1993-2006.

43. Junquera J, Paz O, Sanchez-Portal D, Artacho E. Numerical atomic orbitals for linear-scaling calculations. Phys. Rev. B 2001; 64: 235111.

44. Nose S. A unified formulation of the constant temperature molecular-dynamics methods. J. of Chem. Phys. 1984; 81 (1): 511-519.

45. Rao AM, Eklund PC, Bandow S, Thess A, Smalley RE. Evidence for Charge Transfer in Doped Carbon Nanotube Bundles from Raman Scattering. Nature 1997; 388: 257-259

46. Assael MJ, Metaxa I, Arvanitidis J, Christofilos D, Lioutas C. Thermal conductivity enhancement in aqueous suspensions of carbon multi-walled and double-walled nanotubes in the presence of two different dispersants.Inter. J. of Thermophysics 2005; 26: 647.

47. Gracia-Espino E, López-Urías F, Terrones H, Terrones M. Doping (10, 0)-Semiconductor Nanotubes with Nitrogen and Vacancy Defects. Mater. Express 2011; 1: 127-135.

48. Pereiro M, Baldomir D. Structure and static response of small silver clusters to an external electric field, Phys. Rev. A 2007; 75: 033202. 